\title{
Manejo actual del donante potencial de órganos y tejidos en muerte cerebral: guía de manejo y revisión de la literatura
}

\author{
Ana María Aristizábal ${ }^{1}$, Yuliana Castrillón ${ }^{1}$, Tatiana Gil ${ }^{1}$, David Restrepo ${ }^{1}$, Katherine Solano ${ }^{2}$, \\ Marcela Guevara ${ }^{1}$, Karen Torres ${ }^{3}$, Santiago Cuenca ${ }^{3}$, Jhon Ortiz ${ }^{3}$, Gabriel J. Echeverri ${ }^{4}$
}

Palabras clave: trasplante; trasplante de órganos; selección de donante; obtención de tejidos y órganos; muerte encefálica.

\section{Resumen}

El trasplante de órganos es, en muchos casos, la única opción terapéutica para pacientes con enfermedades terminales de diversos órganos esenciales, sin embargo, existe un acentuado desequilibrio entre el número de órganos disponibles y el de potenciales receptores a nivel mundial.

Los donantes con muerte cerebral son la principal fuente de órganos de trasplante y son esenciales las medidas que promueven su reconocimiento temprano para realizar una gestión clínica apropiada. En este contexto, se sabe que el manejo clínico agresivo del

1 Médico general, estudiante de diplomado en Coordinación Operativa de Trasplantes, Universidad Icesi, Cali, Colombia

2 Enfermera profesional, estudiante de diplomado en Coordinación Operativa de Trasplantes, Universidad Icesi, Cali, Colombia

3 Médico general, Coordinación Operativa de Trasplantes, Clínica Fundación Valle del Lili, Cali, Colombia

4 Especialista en Cirugía de Trasplante de Órganos Abdominales; director, Centro para la Investigación en Cirugía Avanzada y Trasplantes (CICAT), Universidad Icesi, Cali, Colombia

Fecha de recibido: 22 de enero de 2017

Fecha de aprobación: 21 de febrero de 2017

Citar como: Aristizábal AM, Castrillón Y, Gil T, Restrepo D, Solano K, Guevara M, et al. Manejo actual del donante potencial de órganos y tejidos en muerte cerebral: guía de manejo y revisión de la literatura. Rev Colomb Cir. 2017;32:128-45. donante potencial y el uso de protocolos orientados a determinados objetivos se asocia con un mayor número de órganos trasplantados por donante y a la reducción de las pérdidas de potenciales donantes por paro cardiaco.

Colombia es un país con bajos índices de donación y grandes necesidades de trasplantes, con una lista de espera que cada año aumenta exponencialmente. En esta revisión se exponen las recomendaciones internacionales para el manejo del donante potencial con muerte cerebral, las cuales esperamos se puedan adoptar en los protocolos institucionales para optimizar el manejo de nuestros potenciales donantes en Colombia $y$, así, aumentar los trasplantes y suplir las necesidades de nuestros pacientes.

\section{Introducción}

El trasplante de órganos es, en muchos casos, la única opción terapéutica para pacientes con enfermedades terminales de diversos órganos ${ }^{1}$ (figura 1, tabla 1). Existe un acentuado desequilibrio entre el número de órganos disponibles y el de potenciales receptores ${ }^{2}$. En el Reino Unido, Estados Unidos y Europa, el número de potenciales receptores de trasplantes ha aumentado a más de 133.000, mientras que el número de órganos donados de todas las fuentes no está aumentando lo suficiente para mantener este ritmo de crecimiento ${ }^{3-5}$.

Los donantes con muerte cerebral son la principal fuente de órganos de trasplantes. Sin embargo, con la reducción de la mortalidad hospitalaria y el número de 


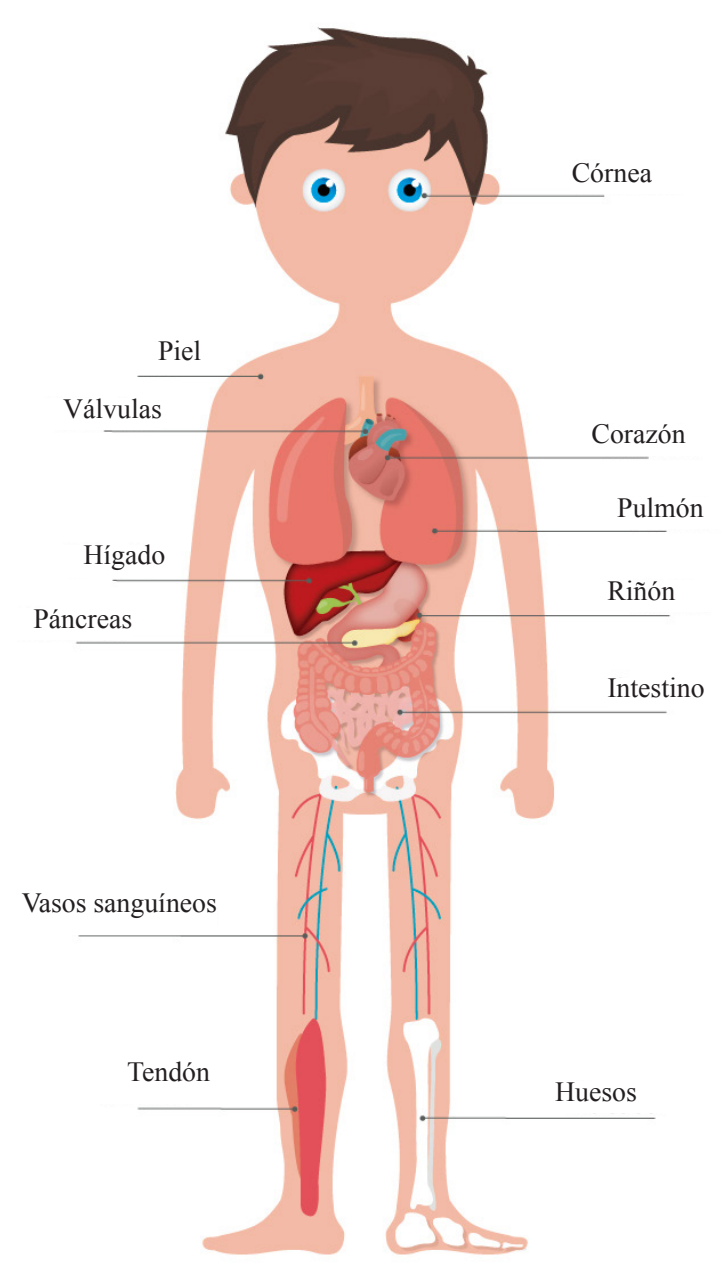

Figura 1. Órganos y tejidos que se pueden donar

pacientes con lesión cerebral que progresa a muerte cerebral en los últimos años, las donaciones después de muerte cerebral también han disminuido, aumentando la disparidad entre la demanda de órganos y el número de trasplantes efectivos ${ }^{2,6}$.

Es importante promover medidas que ayuden al reconocimiento temprano de la muerte cerebral, con el fin de realizar una gestión clínica apropiada y ayudar a mitigar esta disparidad ${ }^{7}$. En este contexto, se sabe que el manejo clínico agresivo del potencial donante y el uso de protocolos orientados a determinados objetivos se asocia con un mayor número de órganos trasplantados por donante y a la reducción de las pérdidas de potenciales donantes por paro cardiaco ${ }^{8-11}$.

El $25 \%$ de los fracasos en la obtención de órganos de donantes con muerte cerebral se le atribuye a la falta de soporte hemodinámico adecuado ${ }^{5}$. El inicio temprano de las acciones de mantenimiento facilita el control hemodinámico y la restauración de la función de los órganos que se van a trasplantar, lo cual permite, en teoría, la planificación de la extracción de los órganos en el momento más oportuno ${ }^{12}$. No obstante, el retrasar su obtención puede conducir a una mayor inflamación sistémica y a un aumento del riesgo de futuro deterioro clínico y paro cardiaco ${ }^{2}$.

Aunque no hay evidencia sobre el efecto del tiempo de mantenimiento en la aparición de paro cardiaco en el donante potencial, las posibilidades de deterioro funcional del injerto justifica la obtención temprana de órganos dentro de un periodo entre 12 y 24 horas después del diagnóstico de muerte cerebral ${ }^{13}$.

Las guías de manejo de donantes con muerte cerebral destacan la importancia de un manejo multidisciplinario en la unidad de cuidados intensivos ${ }^{14,15}$. Se enfatiza la necesidad de la monitorización temprana para guiar la administración de líquidos y evitar la sobrecarga hídrica. Además, se exalta la importancia de que un intensivista experimentado esté directamente involucrado en el cuidado del donante potencial ${ }^{16}$.

Las consecuencias fisiopatológicas típicas de la muerte cerebral incluyen disfunción cardiovascular (hipotensión y arritmias), pulmonar (edema pulmonar, lesiones pulmonares asociadas al respirador), endocrina (diabetes insípida, hiperglucemia), de la termorregulación (poiquilotermia), renal (daño renal agudo), electrolítica (hipernatremia, hiperpotasemia e hipotasemia), hematológica (coagulación intravascular diseminada) y sistémica (reacción inflamatoria sistémica) ${ }^{17}$. En la tabla 2 se muestra la frecuencia de presentación de los diferentes cambios fisiopatológicos ${ }^{18}$.

\section{Trasplantes en Colombia}

Según cifras del Instituto Nacional de Salud de Colombia, entidad de referencia nacional en donación y trasplante de órganos, en el año 2015 hubo un total de 405 donantes reales de órganos, para una tasa nacional de 8,4 donantes por millón de población, en su mayoría, a expensas de donantes cadavéricos ${ }^{19}$.

La lista de espera del Instituto Nacional de Salud al 31 de diciembre del 2015, reportaba 2.029 pacientes 
TABLA 1.

Tejidos que se pueden donar

\begin{tabular}{|c|c|c|c|c|c|c|}
\hline Tejido & $\begin{array}{c}\text { Rango } \\
\text { de } \\
\text { edad }\end{array}$ & $\begin{array}{l}\text { Tiempo } \\
\text { después de } \\
\text { paro }\end{array}$ & $\begin{array}{l}\text { Infecciones que } \\
\text { contraindican la } \\
\text { donación }\end{array}$ & $\begin{array}{l}\text { Neoplasias } \\
\text { que contra- } \\
\text { indican la } \\
\text { donación }\end{array}$ & $\begin{array}{l}\text { Enfermedades que contraindican } \\
\text { la donación }\end{array}$ & $\begin{array}{c}\text { Tiempo de } \\
\text { preservación }\end{array}$ \\
\hline $\begin{array}{l}\text { Ocular } \\
\text { (córnea, } \\
\text { limbo } \\
\text { corneal, } \\
\text { esclera) }\end{array}$ & $\begin{array}{l}\text { Seis } \\
\text { meses - } \\
75 \text { años }\end{array}$ & Hasta 24 horas & $\begin{array}{l}\text { Infección localizada signi- } \\
\text { ficativa (bacteriana, viral, } \\
\text { parasitaria o fúngica), in- } \\
\text { fección ocular por herpes }\end{array}$ & $\begin{array}{l}\text { Retinoblastoma, } \\
\text { tumores malignos } \\
\text { del segmento an- } \\
\text { terior del ojo o del } \\
\text { sistema hematopo- } \\
\text { yético }\end{array}$ & $\begin{array}{l}\text { Inflamación ocular, enfermedades de } \\
\text { tejido conjuntivo o autoinmunitarias, } \\
\text { alteraciones corneales (queratocono, } \\
\text { queratoglobo o distrofia) } \\
\text { Opacidad corneal, cicatrices, pterigion } \\
\text { Cirugía previa que perjudique el injerto, } \\
\text { cirugía de refracción }\end{array}$ & $\begin{array}{l}\text { Hasta 3-7 días } \\
\text { dependiendo } \\
\text { del método de } \\
\text { preservación }\end{array}$ \\
\hline Piel & $\begin{array}{l}<60 \\
\text { años }\end{array}$ & $\begin{array}{l}\text { Hasta } 24 \text { horas } \\
\text { si el cuerpo fue } \\
\text { refrigerado en } \\
\text { las primeras } 6 \\
\text { horas de muerte } \\
\text { o } 15 \text { horas si no } \\
\text { ha sido refrige- } \\
\text { rado }\end{array}$ & Piodermas o micosis & $\begin{array}{l}\text { Presencia de po- } \\
\text { sibles melanomas }\end{array}$ & $\begin{array}{l}\text { Enfermedades de tejido conjuntivo o au- } \\
\text { toinmunitarias, daño mecánico de la piel, } \\
\text { quemaduras, intoxicaciones, diabetes de } \\
\text { más de10 años con complicaciones }\end{array}$ & $\begin{array}{l}\text { Hasta } 5 \text { años } \\
\text { dependiendo } \\
\text { del método de } \\
\text { preservación }\end{array}$ \\
\hline $\begin{array}{l}\text { Músculoes- } \\
\text { quelético } \\
\text { (óseo, fascia, } \\
\text { tendones y } \\
\text { meniscos) }\end{array}$ & $\begin{array}{l}\text { - Hueso: } \\
>15 \\
\text { años } \\
\text {-Ten- } \\
\text { dones: } \\
\text { 15-65 } \\
\text { años } \\
\text {-Me- } \\
\text { niscos: } \\
15-45 \\
\text { años }\end{array}$ & $\begin{array}{l}\text { Hasta } 24 \text { horas } \\
\text { si el cuerpo fue } \\
\text { refrigerado en } \\
\text { las primeras } 6 \\
\text { horas de muerte } \\
\text { o } 15 \text { horas si no } \\
\text { ha sido refrige- } \\
\text { rado }\end{array}$ & $\begin{array}{l}\text { Infección bacteriana, viral, } \\
\text { parasitaria o fúngica local }\end{array}$ & Sarcoma & $\begin{array}{l}\text { Enfermedades óseas metabólicas (osteo- } \\
\text { porosis, osteopetrosis, enfermedad de } \\
\text { Paget), ingestión de cianuro o metales pe- } \\
\text { sados (mercurio, oro, etc.), enfermedades } \\
\text { de tejido conjuntivo o autoinmunitarias, } \\
\text { sarcoidosis, evidencia de trauma local } \\
\text { o fracturas }\end{array}$ & $\begin{array}{l}\text { Hasta } 5 \text { años } \\
\text { dependiendo } \\
\text { del método de } \\
\text { preservación }\end{array}$ \\
\hline $\begin{array}{l}\text { Cardiovascu- } \\
\text { lar (válvulas, } \\
\text { segmentos } \\
\text { arteriales) }\end{array}$ & $\begin{array}{l}\text {-Vasos: } \\
<55 \\
\text { años } \\
\text {-Válvu- } \\
\text { las: }<65 \\
\text { años }\end{array}$ & $\begin{array}{l}\text { Hasta } 24 \text { horas } \\
\text { si el cuerpo fue } \\
\text { refrigerado en } \\
\text { las primeras } 6 \\
\text { horas de muerte } \\
\text { o } 15 \text { horas si no } \\
\text { ha sido refrige- } \\
\text { rado }\end{array}$ & $\begin{array}{l}\text { Endocarditis bacteriana } \\
\text { o fúngica, neumonía sin } \\
\text { tratamiento efectivo } \\
\text { Cultivos positivos en mues- } \\
\text { tras de tejido miocárdico } \\
\text { (Clostridium sp., Entero- } \\
\text { coccus sp., Flavobacte- } \\
\text { rium meningosepticum, } \\
\text { Klebsiella rhinosceromatis, } \\
\text { Listeria monocytogenes, } \\
\text { Neisseria gonorrohoeae, } \\
\text { Nocardia sp., Pseudomo- } \\
\text { nas aeruginosa, Staphylo- } \\
\text { coccus aureus, Salmonella } \\
\text { sp., Candida } \mathrm{sp} ., \text { Mucor } \\
\text { sp., Penicillium sp., Myco- } \\
\text { bacteria } \mathrm{sp} . \text { ) }\end{array}$ & $\begin{array}{l}\text { Iguales que para } \\
\text { donantes de órga- } \\
\text { nos y tejidos }\end{array}$ & $\begin{array}{l}\text { Valvulopatías de la pulmonar o aórtica } \\
\text { moderadas a graves, enfermedades de } \\
\text { tejido conjuntivo o autoinmunitarias, } \\
\text { disección aórtica, síndrome de Marfan, } \\
\text { trauma abierto en el área de obtención, } \\
\text { dilatación miocárdica, cirugías cardiacas } \\
\text { previas }\end{array}$ & $\begin{array}{l}\text { Hasta } 5 \text { años } \\
\text { dependiendo } \\
\text { del método de } \\
\text { preservación }\end{array}$ \\
\hline $\begin{array}{l}\text { Membrana } \\
\text { amniótica }\end{array}$ & $\begin{array}{l}18-45 \\
\text { años }\end{array}$ & $\begin{array}{l}\text { Obtención des- } \\
\text { pués de la ce- } \\
\text { sárea/24 horas }\end{array}$ & $\begin{array}{l}\text { Infección grave del aparato } \\
\text { genital o del líquido amnió- } \\
\text { tico, endometritis }\end{array}$ & $\begin{array}{l}\text { Iguales que para } \\
\text { donantes de órga- } \\
\text { nos y tejidos }\end{array}$ & $\begin{array}{l}\text { Diabetes de la gestación, malformacio- } \\
\text { nes conocidas del recién nacido, ruptura } \\
\text { prematura de membranas, íleo meconial }\end{array}$ & $\begin{array}{l}\text { Hasta } 1 \text { año } \\
\text { dependiendo } \\
\text { del método de } \\
\text { preservación }\end{array}$ \\
\hline
\end{tabular}

que necesitaban órganos sólidos para trasplante y se practicaron 1.204 trasplantes en el país en ese año ${ }^{19}$, lo que demuestra la carencia de órganos suficientes para suplir las necesidades. En las figuras 2 y 3 se evidencia la variación de la tasa de donantes y de trasplantes, y el aumento de la lista activa de espera de trasplantes en los últimos años en Colombia.

\section{Legislación colombiana}

En Colombia existe una amplia reglamentación de todos los aspectos relacionados con la donación y el trasplante de componentes anatómicos, entre ellas, la Ley 73 de 1988, la Ley 919 de 2004 y el Decreto 2493 de 2004, como las más importantes. El Decreto 2493 


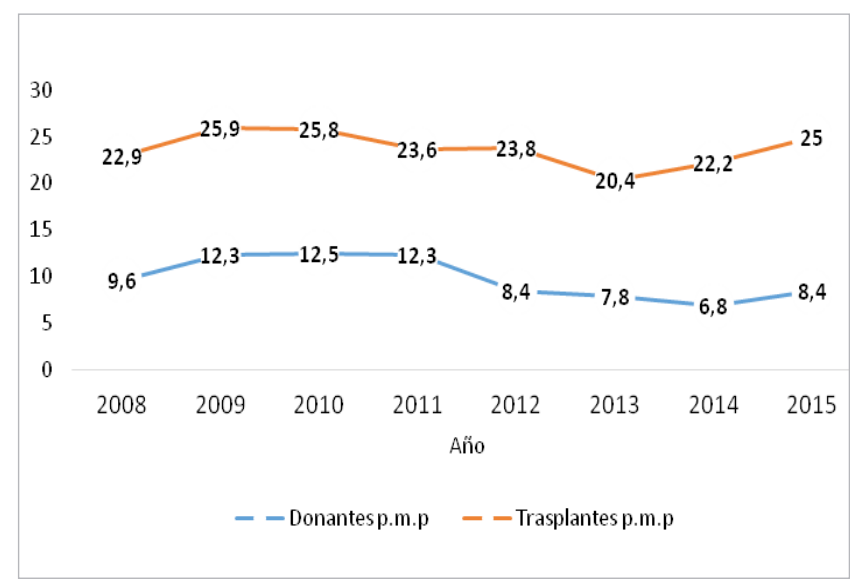

Fuente: Instituto Nacional de Salud

FIgURA 2. Variación de la tasa de donantes y la tasa de trasplantes en Colombia por millón de población

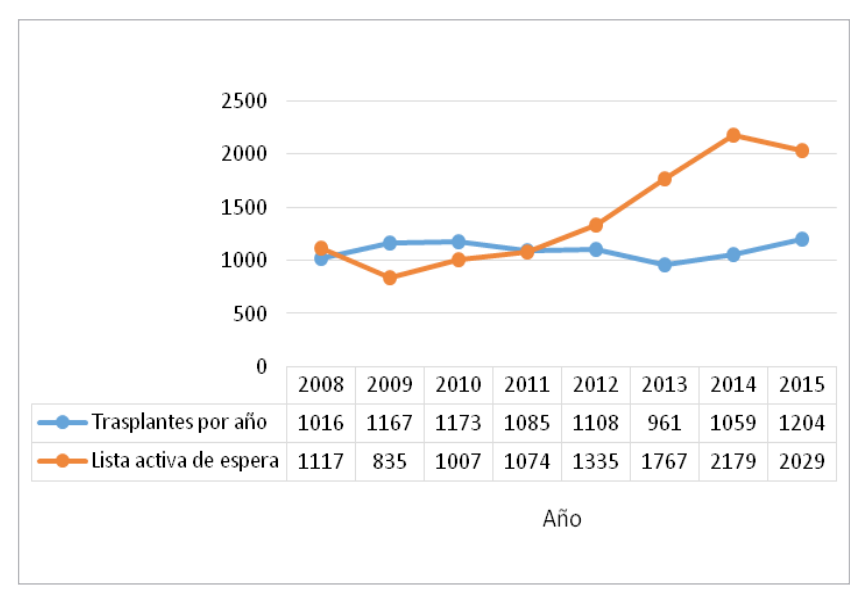

Fuente: Instituto Nacional de Salud

Figura 3. Variación del número de trasplantes y el número de pacientes en lista activa de espera de trasplantes en los últimos años en Colombia

de 2004, "Regula la obtención, donación, preservación, almacenamiento, transporte, destino y disposición final de componentes anatómicos y los procedimientos de trasplante o implante de los mismos en seres humanos".

Estas normativas regulan los procesos para la donación de órganos y tejidos de personas fallecidas o vivas con fines de trasplante, los mecanismos de donación, los aspectos técnico-científicos y las medidas sanitarias en caso de incumplimientos.

Recientemente, el Congreso de la República expidió la Ley 1805 de 2016, por medio de la cual se modifican la Ley 73 de 1988 y la Ley 919 de 2004, ampliando la presunción legal de componentes anatómicos para fines de trasplantes u otros usos terapéuticos. Esta ley pretende brindar mayores oportunidades para aquellas personas que padecen enfermedades crónicas terminales, atribuyendo la facultad de oponerse a la donación de componentes anatómicos únicamente a la persona que en vida así lo hubiere manifestado formalmente. Además, exige a las instituciones prestadoras de salud (IPS) contar con la capacidad técnica necesaria para detectar oportunamente a los potenciales donantes de acuerdo con los criterios y competencias que establezca el Instituto Nacional de Salud.

\section{Red de trasplantes en Colombia}

La Red de Donación y Trasplantes de Órganos y Tejidos fue creada por el Ministerio de la Protección Social en el año 2004, mediante el Decreto 2493. Es un sistema de integración de los Bancos de Tejidos y Médula Ósea, IPS habilitadas con programas de trasplantes o implantes, el Instituto Nacional de Salud, las Direcciones Departamentales y Distritales de Salud, y demás entidades del sistema. Busca la coordinación de actividades relacionadas con la promoción, la donación, la extracción, el trasplante y el implante de órganos y tejidos, con el objeto de hacerlos accesibles en condiciones de calidad, en forma oportuna y suficiente a la población, siguiendo los principios de cooperación, eficacia, eficiencia, equidad y solidaridad.

El Instituto Nacional de Salud, como coordinador de la Red, realiza sus funciones de coordinación nacional; para su funcionamiento se dividió al país en seis regionales:

- Regional 1: con sede en Bogotá, D.C., está integrada por Cundinamarca, Tolima, Boyacá, Casanare, Meta, Caquetá, Vichada, Vaupés, Guaviare, Guainía, Putumayo y Amazonas.

- Regional 2: con sede en Medellín, está integrada por Antioquia, San Andrés y Providencia, Chocó, Córdoba y Caldas.

- Regional 3: con sede en Santiago de Cali, está integrada por el Valle del Cauca, Cauca, Nariño, Risaralda y Quindío.

- Regional 4: con sede en Bucaramanga, está integrada por Santander, Norte de Santander, Cesar y Arauca. 
- Regional 5: con sede en Barranquilla, está integrada por Atlántico, Bolívar, Magdalena, La Guajira y Sucre.

- Regional 6: con sede en Neiva, corresponde al departamento del Huila.

Cada regional cuenta con una coordinación regional y, a su vez, con coordinadores operativos de trasplantes en las principales ciudades que, unidos a la coordinación nacional, vigilan el adecuado funcionamiento de la Red.

Las IPS donde exista un potencial donante de órganos deben notificar a la red regional de trasplantes a través del personal médico responsable del paciente; de igual forma, deben permitir los procedimientos requeridos por los médicos coordinadores operativos, y por el personal médico y paramédico que realice el rescate de dichos órganos y tejidos (Decreto 2493, artículo 23). Dicha reglamentación fortalece el desarrollo del procedimiento en todo el territorio colombiano, generando un ámbito de seguridad y claridad en las IPS.

\section{Experiencia en la Clínica Fundación Valle del Lili}

En el año 2015, la principal ciudad generadora de donantes fue Medellín (27,4 \%). Sin embargo, la Clínica Fundación Valle del Lili de Cali generó la mayor cantidad de donantes (7,9\% de los donantes reales), seguida del Hospital Pablo Tobón Uribe y el Hospital Universitario San Vicente de Paúl de Medellín, con el 5,4 \% cada uno ${ }^{19}$.

La Fundación Valle del Lili cuenta con una amplia experiencia en trasplantes ${ }^{20-30}$. Es una institución en donde desde hace más de 20 años está en marcha el programa de trasplantes; es la única IPS en Colombia donde se practica el trasplante de riñón y páncreas y, en la actualidad, se realizan trasplantes de hígado, páncreas, islotes pancreáticos, riñones, intestino, pulmón y corazón (figura 4).

\section{Diagnóstico de muerte por criterios cerebrales}

Con el advenimiento de la tecnología en las unidades de cuidados intensivos y, particularmente, del pulmón artificial en 1959, el cual permitió el control externo de la función respiratoria sin que para ello medie la voluntad del individuo o el mecanismo reflejo de la respiración, se evidenció una nueva situación clínica neurológica a la

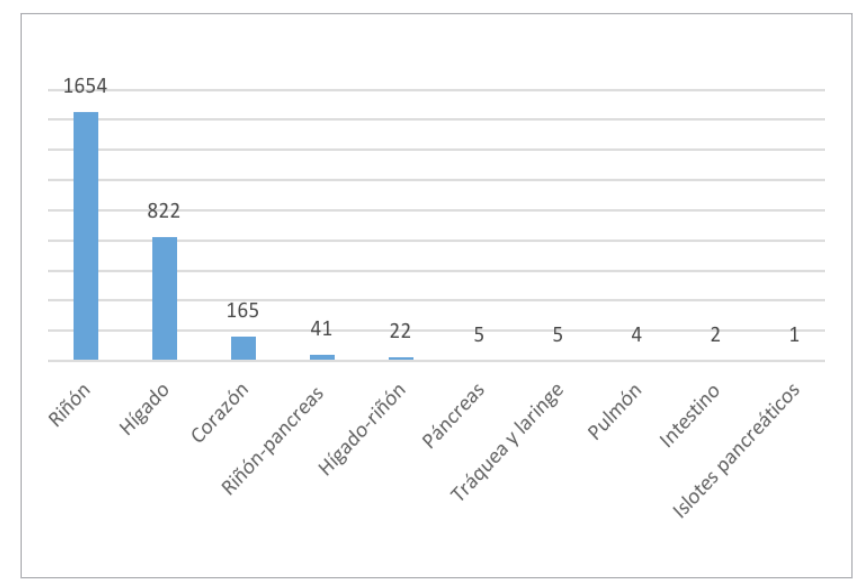

Fuente: Unidad de trasplantes, Fundación Valle de Lili

Figura 4. Número de trasplantes a 31 de diciembre de 2016 en la Fundación Valle del Lili

que Goulon y Mollaret en Francia denominaron 'coma depassé' (del que no se regresa) ${ }^{31,32}$. Este se caracteriza por un coma profundo arreactivo con ausencia de reflejos del tallo cerebral, en el cual la función respiratoria y el estado hemodinámico del paciente se mantienen por medios externos artificiales.

Sistemáticamente, se fue comprobando por todo el mundo, que este coma depassé representaba una situación neurológica irrecuperable y que inexorablemente estaba seguida, en cuestión de horas o días, por la asistolia irreversible, a pesar de las más concienzudas medidas de mantenimiento. El examen histopatológico de estos individuos mostraba necrosis y descomposición del sistema nervioso central, similar a lo observado en los pacientes que sufren muerte clásica por paro cardiorrespiratorio. Finalmente, el concepto de coma depassé dio paso al de muerte cerebral, según los criterios de Harvard, en $19688^{33}$.

Desde entonces, el concepto de muerte cerebral se ha ido construyendo y modificando a lo largo del tiempo, y ha sido aceptado por la comunidad científica y la legislación de diferentes países. Actualmente, se entiende como "el cese irreversible de todas las funciones del tallo cerebral y la corteza comprobado por un examen neurológico clínico" ${ }^{34}$. Dicho diagnóstico cumple los siguientes criterios: lesión estructural cerebral definitiva y de etiología conocida, ausencia de reflejos del tallo encefálico y apnea ${ }^{35}$. 
Dada la importancia ética y médico-legal, para hacer el diagnóstico se debe certificar la exclusión de condiciones clínicas que simulen la muerte cerebral, como: alteraciones en la oxigenación-hipoxemia, graves alteraciones electrolíticas, metabólicas o endocrinas (hipotermia $<32{ }^{\circ} \mathrm{C}$, hipoglucemia, hipofosfatemia, hipotiroidismo), intoxicación o estar bajo efecto de medicación neurodepresora (sedantes, anestésicos, barbitúricos o relajantes musculares) ${ }^{16,34}$.

La legislación colombiana a lo largo del tiempo ha establecido quiénes pueden ser donantes y los criterios clínicos que deben cumplir. Actualmente, el Decreto 2493 del 2004 rige las pautas que se deben tener presentes para el diagnóstico de muerte cerebral en Colombia. Indica que debe hacerse por dos o más médicos, uno de los cuales debe ser neurólogo o neurocirujano. Ninguno de ellos puede pertenecer al programa de trasplantes, ya que esto podría generar conflicto de interés. Dichas actuaciones deben constar por escrito en la historia clínica, indicando la valoración de los siete signos y el diagnóstico definitivo de muerte cerebral ${ }^{36}$.

El objetivo de la evaluación neurológica es determinar la ausencia de los reflejos de tallo encefálico en la muerte cerebral:

1. pupilas persistentemente dilatadas,

2. ausencia de reflejos pupilares a la luz,

3. ausencia de reflejo corneano,

4. susencia de reflejos óculo-vestibulares,

5. ausencia de reflejo faríngeo o nauseoso,

6. ausencia de reflejo tusígeno, y

7. ausencia de respiración espontánea.

\section{Prueba de apnea}

Se recomienda continuar la valoración del potencial donante realizando el test de apnea. Su objetivo es estimular el centro respiratorio del tronco encefálico para corroborar la ausencia de respiración espontánea. Es necesario conseguir un estímulo suficiente para activar el centro respiratorio; generalmente, esto se logra al alcanzar una presión parcial de dióxido de carbono $\left(\mathrm{PaCO}_{2}\right) \geq 60 \mathrm{~mm} \mathrm{Hg}^{34}$.
Inicialmente, se debe verificar la estabilidad hemodinámica del paciente (presión arterial sistólica $\geq 100 \mathrm{~mm}$ $\mathrm{Hg}$ ), habiendo administrado previamente, por lo menos durante 10 minutos, oxígeno al $100 \%$ para alcanzar una presión parcial de oxígeno $\left(\mathrm{PaO}_{2}\right) \geq 200 \mathrm{~mm} \mathrm{Hg}$.

Seguidamente, se debe realizar una gasometría arterial para verificar la cifra de $\mathrm{PaCO}_{2}$ y calcular el tiempo que el paciente debe estar desconectado del respirador para alcanzar niveles de $\mathrm{PaCO}_{2}$ suficientes para estimular el centro respiratorio (generalmente, entre 8 y 10 minutos) ${ }^{35}$.

Posteriormente, se desconecta al paciente del respirador y se introduce a través del tubo endotraqueal una sonda de nélaton delgada (máximo $30 \%$ del diámetro del tubo) conectada a una fuente de oxígeno a 6 litros por minuto. Se deben observar el tórax y el abdomen, comprobando que no exista ningún tipo de movimiento respiratorio durante el tiempo previamente calculado para lograr la estimulación del centro respiratorio. Durante este periodo, debe haber monitoría continua de la saturación de oxígeno, la presión arterial y el ritmo cardiaco. Inmediatamente después, se toma una nueva gasometría arterial, previa a la reconexión del respirador. Esta prueba se interpretará como correspondiente a muerte cerebral si hay ausencia de movimiento o esfuerzo respiratorio y si se provoca un aumento de la $\mathrm{PaCO}_{2} \geq 60 \mathrm{~mm} \mathrm{Hg} \mathrm{o}$ superior a $20 \mathrm{~mm} \mathrm{Hg}$ de su valor basal ${ }^{35}$.

TABLA 2.

Frecuencia de presentación de los cambios fisiopatológicos con muerte cerebral

\begin{tabular}{llc}
\hline \multicolumn{1}{c}{ Causa } & $\begin{array}{c}\text { Frecuencia } \\
(\%)\end{array}$ \\
\hline Hipotermia & $\begin{array}{l}\text { Disfunción hipotalámica, } \\
\text { vasoplejía }\end{array}$ & 100 \\
\hline Hipotensión & $\begin{array}{l}\text { Vasoplejía, hipovolemia, } \\
\text { disfunción miocárdica }\end{array}$ & $80-97$ \\
\hline Diabetes insípida & $\begin{array}{l}\text { Disfunción hipotalámica/ } \\
\text { pituitaria }\end{array}$ & $65-90$ \\
\hline Arritmias & $\begin{array}{l}\text { Liberación de catecolami- } \\
\text { nas, injuria miocárdica }\end{array}$ & $25-32$ \\
\hline Edema pulmonar & $\begin{array}{l}\text { Injuria del endotelio } \\
\text { vascular }\end{array}$ \\
\hline Paro cardiaco & $\begin{array}{l}\text { Hipotensión prolongada, } \\
\text { arritmias }\end{array}$ & $5-10$ \\
\hline
\end{tabular}

Extraído de: Hahnenkamp, et al. ${ }^{18}$ 
Si se considera que el potencial donante cumple los criterios para la donación de pulmón, se debe procurar al máximo no desconectarlo del respirador. En estos casos, se puede practicar la prueba de apnea con una válvula de presión positiva continua en la vía aérea, con el fin de asegurar una mejor oxigenación y disminuir el riesgo de complicaciones que se pueden presentar con el método tradicional, tales como la despresurización en la vía aérea y el aumento del colapso alveolar ${ }^{37}$.

Se deben tener en cuenta algunos requisitos previos al test de apnea, para disminuir los riesgos de complicaciones y evitar lesiones iatrogénicas durante el mismo; entre estos, están mantener la euvolemia, la normocapnia, la normoxemia y una temperatura $\geq 36{ }^{\circ} \mathrm{C}{ }^{16}$. En caso de que durante la prueba se presente una arritmia cardíaca, hipotensión con PAS $\leq 90 \mathrm{~mm} \mathrm{Hg}$, desaturación significativa $(\mathrm{SpO} 2 \leq 85 \%)$ o presencia de movimientos respiratorios autonómicos, se debe suspender de inmediato el procedimiento ${ }^{3}$.

\section{Prueba de certeza}

Cuando no sea posible valorar algún reflejo o practicar la prueba de apnea, el Decreto 2493 del 2004 recomienda aplicar una prueba de certeza o estudio imagenológico complementario, tal como la ecografía Doppler transcraneal, la arteriografía cerebral por sustracción digital o la gammagrafía de perfusión cerebral, las cuales evaluarían el paro circulatorio sanguíneo cerebral (figura 5). También, pueden hacerse pruebas que midan la actividad eléctrica neuronal, como el electroencefalograma o los potenciales auditivos evocados $35,38,39$.

En el caso del diagnóstico de muerte cerebral en pacientes pediátricos, se tienen en cuenta consideraciones especiales

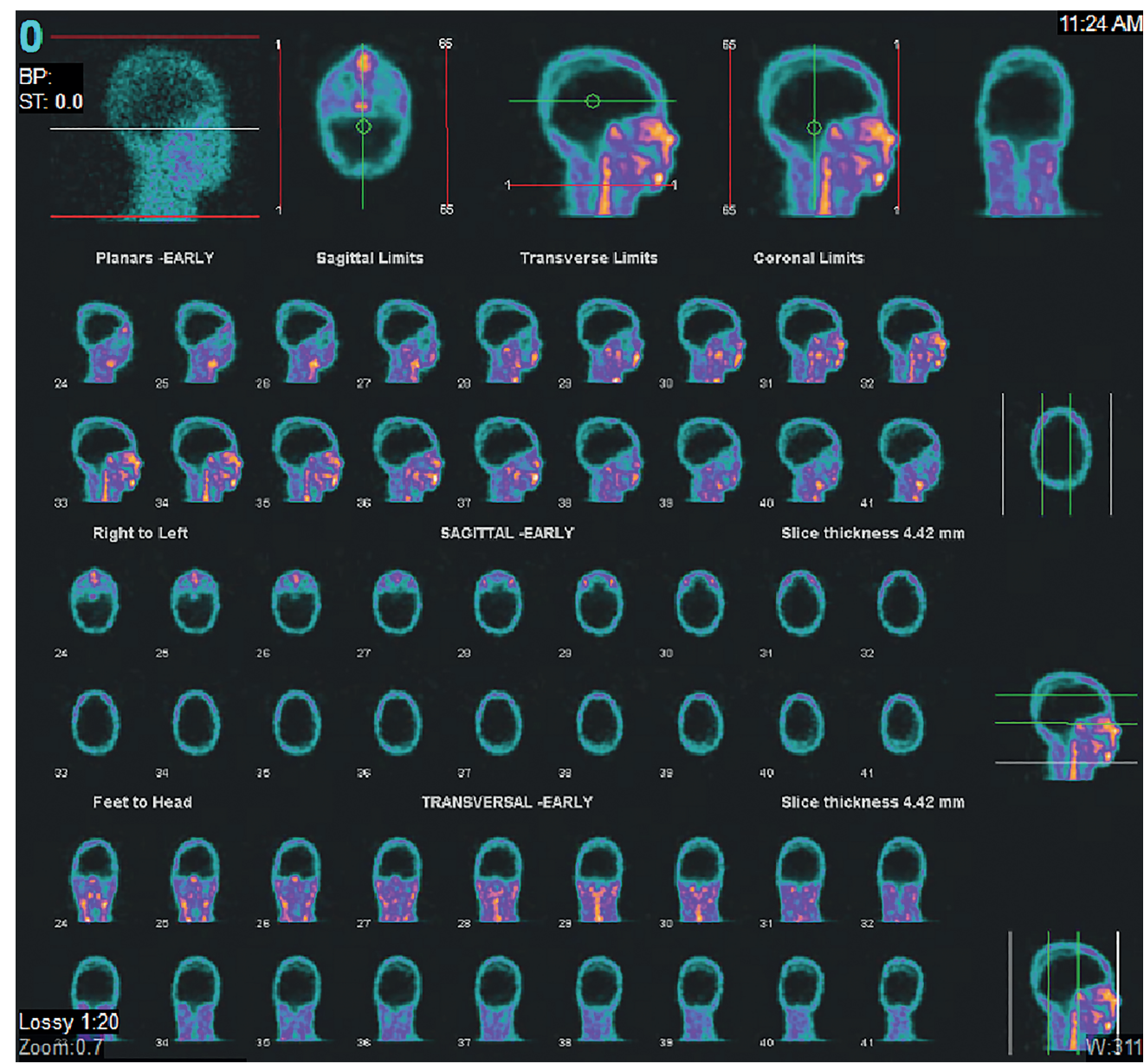

Fuente: Unidad de Radiología, Fundación Valle del Lili

FIGURA 5. Gammagrafía cerebral con leucocitos marcados con 99mTc-HMPAO. No se observa concentración del trazador en el parénquima cerebral (signo de la calota vacía) 
sujetas a la legislación colombiana ${ }^{36,40}$. El periodo de observación varía con la edad. En niños entre siete días y dos meses de edad, se requieren dos exploraciones clínicas con electroencefalogramas separados por 48 horas. En niños de dos meses a dos años, se realizan dos exploraciones clínicas con electroencefalogramas separados por 24 horas. En los mayores de dos años, es válido aplicar los mismos criterios diagnósticos que en el adulto.

\section{Mantenimiento del potencial donante con muerte cerebral}

\section{Cambios del sistema nervioso central}

La muerte cerebral se asocia con una cascada característica de cambios fisiológicos, que conducen a importantes cambios hormonales, inflamatorios y hemodinámicos.

\section{Cambios hormonales}

La isquemia hipofisiaria lleva a una disminución de los niveles plasmáticos de las hormonas pituitarias. En los estudios de Chen, et al. ${ }^{41}$, realizados en animales, se documenta que los niveles de vasopresina (ADH) son indetectables a las seis horas después del diagnóstico de muerte cerebral, mientras que la corticotropina (ACTH) y la hormona tirotropina (TSH) permanecen constantes por más de 16 horas; la triyodotiroxina (T3) disminuye en más del $50 \%$ en la primera hora y es indetectable nueve horas después de la muerte cerebral.

La deficiencia de hormonas pituitarias, especialmente el hipotiroidismo, se asocia con agotamiento de la energía miocárdica, cambio a metabolismo anaerobio y reducción de la función cardíaca ${ }^{42}$.

En un estudio en humanos, Salim, et al. ${ }^{43}$, observaron una mejoría significativa en los perfiles hemodinámicos de los pacientes con muerte cerebral tratados con T3, cortisol e insulina. Además, Rosendale, et al. ${ }^{44}$, demostraron una reducción significativa en la terapia vasopresora después de la administración de tetrayodotironina (T4). Desde entonces, múltiples investigadores han reportado los efectos cardiovasculares de la reanimación hormonal; por ejemplo, con la terapia hormonal, Novitzky, et al. ${ }^{45}$, evidenciaron mejoría del perfil hemodinámico con reducción de la necesidad de vasopresores y mayor probabilidad de que el órgano sea apto para el trasplante.
Se ha evidenciado que el tratamiento con una combinación de hormonas que incluya T3, lograría revertir la disfunción cardiaca después de la muerte cerebral y podría ser capaz de restaurar el metabolismo aerobio ${ }^{45}$. Estas observaciones han dado lugar a un mayor interés en la aplicación clínica del reemplazo de la hormona tiroidea, con el objetivo de promover la estabilidad hemodinámica y mejorar la función cardíaca ${ }^{46}$.

La terapia de reemplazo hormonal se debe considerar en pacientes con inestabilidad hemodinámica y en donantes cardiacos con una fracción de eyección ventricular izquierda (FEVI) menor de $45 \%$. Se recomienda la T3, ya que tiene un inicio de acción más rápido en comparación con la T4 y es menos sensible a factores exógenos que interfieren en la conversión de T4 a T3. No obstante, tanto T3 como T4 son aceptables para la terapia de reemplazo hormonal.

En varios estudios, Novitzky, et al. ${ }^{47}$, han demostrado que la terapia con T3 o T4 se asocia con un mayor número de órganos trasplantados, sin que generen efectos perjudiciales en la supervivencia del injerto después del trasplante. En uno de estos estudios ${ }^{48}$, se evaluó de forma retrospectiva la información sobre la terapia de reemplazo hormonal en 63.593 donantes a quienes se les administró T3 o T4 y se encontró que el porcentaje de todos los órganos procurados, excepto el de hígado, fue mayor cuando se administraron dichas hormonas.

Un protocolo comúnmente utilizado es el de administrar un bolo de $20 \mu \mathrm{g}$ de T4 intravenoso, seguido de infusión continua a $10 \mu \mathrm{g} /$ hora, o administrar un bolo de 4,0 $\mu \mathrm{g}$ de T3 intravenoso, seguido de una infusión continua a $3 \mu \mathrm{g} /$ hora $^{34}$.

Además, en los pacientes con muerte cerebral y debido al daño a las estructuras de la hipófisis posterior, el hipotálamo, los núcleos supraópticos y los núcleos paraventriculares, se genera reducción precoz de la vasopresina y se desarrolla diabetes insípida hasta en $80 \%$ de los casos ${ }^{46,49}$ (tabla 3 ). La falta de vasopresina impide que el túbulo renal reabsorba agua libre, lo cual genera poliuria con volúmenes de orina tan grandes como 500 $\mathrm{ml} /$ hora. Esto puede llevar a perpetuar una situación de hipovolemia, hipotensión, hiponatremia y otras alteraciones hidroelectrolíticas ${ }^{2,50}$. 
TABLA 3.

Cuándo considerar el tratamiento para la deficiencia de vasopresina

1. Hipotensión persistente a pesar de reanimación volumétrica adecuada

2. Ante la presencia de diabetes insípida (uno o más de los siguientes criterios):
A. Poliuria (gasto urinario $>3-4 \mathrm{~L} /$ día o 2,5-3,0 ml/ $\mathrm{kg} / \mathrm{hora}$ )
B. Osmolaridad sérica normal o aumentada
C. Dilución urinaria inapropiada (densidad urinaria $<1.005$, osmolaridad urinaria $<200 \mathrm{mOsm} / \mathrm{kg} \mathrm{H}_{2} \mathrm{O}$ )
D. Hipernatremia $(\mathrm{Na}+>145 \mathrm{mmol} / \mathrm{L})(34)$

La vasopresina ejerce varios efectos terapéuticos vinculando a tres receptores de vasopresina acoplados a la proteína $\mathrm{G}$ : los receptores $\mathrm{V} 1$ en el músculo liso vascular median el efecto vasopresor, al inducir la contracción del músculo liso vascular; los receptores V2 en la membrana basolateral de la nefrona del túbulo colector, controlan las acuaporinas y promueven un efecto antidiurético; y el receptor $\mathrm{V} 3$, expresado en la glándula pituitaria anterior, se une para ejercer sinergismo con la tiroliberina (TRH) en la regulación y la producción de corticotropina ${ }^{34}$.

En estudios clínicos, Chen, et al. ${ }^{51}$, y Pennefather, et al. ${ }^{52}$, han demostrado que la administración de vasopresina se asocia con mejoría de la presión arterial y reduce la necesidad de vasopresores e inotrópicos. El esquema ideal de dosificación de la vasopresina para posibles donantes de órganos no se ha establecido claramente. Holmes, et al. ${ }^{53}$, han sugerido que la velocidad de infusión en otros tipos de choque por vasodilatación (por ejemplo, el choque séptico) debe limitarse a un máximo de 0,03 a $0,04 \mathrm{UI} /$ minuto, debido a que dosis más altas pueden estar asociadas con efectos cardiacos adversos ${ }^{53}$. Sin embargo, en un estudio prospectivo de Torgersen, et al. ${ }^{54}$, se sugiere que una tasa de infusión mucho mayor ( $0,067 \mathrm{UI} /$ minuto) es más eficaz en el restablecimiento de la estabilidad hemodinámica en el choque por vasodilatación.

La desmopresina es un análogo de la vasopresina con una afinidad significativamente mayor por el receptor V2 que por V1. Por lo tanto, este es el fármaco de elección en el tratamiento de la diabetes insípida sin hipotensión, ya que su actividad primaria es el efecto antidiurético y su reacción vasopresora es mínima ${ }^{55}$.
TABLA 4.

Tratamiento de la diabetes insípida

a) Reposición del $50 \%$ de la diuresis obtenida previamente, con solución de lactato de Ringer o solución salina isotónica

b) Mantener una volemia o precarga adecuada (PVC 4-8 mm Hg).

c) Manejo de hipernatremia $(\mathrm{Na} \geq 150 \mathrm{mEq} / \mathrm{L})$

- Restricción del aporte de sodio

- Uso de solución salina al 0,45 \% o solución de glucosa al 3-5\% en vez de solución salina isotónica, lactato de Ringer o lactato para reponer la diuresis

d) Uso de análogos de la vasopresina frente a una diuresis mayor de $300 \mathrm{ml} /$ hora asociada a hipotensión o hipernatremia Vasopresina

Desmopresina

En la práctica, se administra una dosis inicial de 1 a $4 \mu \mathrm{g}$, se vigila la osmolalidad urinaria, el gasto urinario (con meta de menos de $4 \mathrm{ml} / \mathrm{kg} /$ hora) y la concentración sérica de sodio, con el fin de vigilar la reacción al fármaco, y evitar la retención de líquidos y la hiponatremia (tabla 4). Al mejorar el gasto urinario, se recomienda administrar una dosis adicional de desmopresina; normalmente, se requieren 1 a $2 \mu \mathrm{g}$ intravenosos cada seis horas. La desmopresina aumenta las concentraciones de factores procoagulantes (factor VIII y de von Willebrand), por lo cual también se ha utilizado como agente hemostático; la dosis recomendada para inducir efectos procoagulantes es significativamente mayor $(0,3 \mu \mathrm{g} / \mathrm{kg})^{56}$.

\section{Cambios inflamatorios}

Después de la lesión inicial, se genera una reacción inflamatoria sistémica. En esta, hay inflamación del sistema nervioso central como reacción a la lesión neural e inflamación de los órganos debida a la formación de radicales libres durante la tormenta autonómica que se genera como consecuencia de la muerte cerebral ${ }^{57}$.

McKeating, et al. ${ }^{58}$, demostraron que hay aumento de la interleucina 6 (IL-6) en humanos después de una hemorragia subaracnoidea o un trauma craneoencefálico. La IL-6 es una citocina proinflamatoria y su aumento se asocia con malos resultados en los pacientes.

Stangl, et al. ${ }^{59}$, observaron diferencias en los niveles sanguíneos de citocinas proinflamatorias (IL-6, IL-8 y $\mathrm{TNF}-\alpha$ ) en donantes con muerte cerebral, en comparación 
con donantes vivos. Se ha observado que esta elevación persiste, incluso después de la extracción de órganos, lo que sugiere que los niveles de citocinas inflamatorias son mayores en los donantes con muerte cerebral en comparación con los donantes vivos. Lo anterior tiene gran relevancia, ya que se ha demostrado que este estado proinflamatorio puede afectar negativamente la función del injerto tras el trasplante de corazón, pulmón o hígado.

Debido al cese del funcionamiento del eje hipotálamohipófisis-suprarrenales, existe una insuficiencia esteroidea absoluta. El tratamiento del donante con altas dosis de corticosteroides para reducir la inflamación inducida por la muerte cerebral, puede mejorar la calidad de los órganos de los donantes y, por lo tanto, la función del injerto después del trasplante. Follette, et al. ${ }^{60}$, reportaron que el uso de corticosteroides mejora la oxigenación del pulmón (mayores relaciones $\mathrm{PaO}_{2} / \mathrm{FiO}_{2}$ ) y la función cardiaca después del trasplante, y atenúa los efectos proinflamatorios.

Otros autores han informado que el tratamiento con corticosteroides previo a la donación de órganos, ya sea solo o en combinación (con vasopresina o desmopresina y hormona tiroidea), puede tener efectos benéficos sobre la función del injerto después del trasplante renal o cardíaco. Además, McElhinney, et al. ${ }^{61}$, demostraron que el tratamiento con metilprednisolona es un factor predictor de trasplante pulmonar exitoso.

Se recomienda la administración de dosis altas de corticosteroides (metilprednisolona intravenosa: 1,000 $\mathrm{mg}, 15 \mathrm{mg} / \mathrm{kg}$ o $250 \mathrm{mg}$ seguidos de infusión a 100 $\mathrm{mg} /$ hora). Este tratamiento podría reducir el potencial daño que genera la cascada inflamatoria sobre la función de los órganos después de la muerte cerebral. Lo ideal sería administrarlo después de que la sangre haya sido recolectada para la tipificación de tejidos, ya que tiene el potencial de suprimir la expresión del antígeno leucocitario humano (HLA) ${ }^{34}$.

\section{Hipotermia}

La disfunción hipotalámica también produce pérdida del control de la temperatura e hipotermia. El centro de regulación térmica se encuentra localizado en grupos neuronales del núcleo preóptico del hipotálamo anterior. Este recibe información de receptores térmicos cutáneos y de grandes vasos, de las vísceras y de la médula espinal, además de la temperatura de la sangre que perfunde el hipotálamo.
La hipotermia puede producir arritmias, coagulopatía y disfunción cardiaca, y dificultar el diagnóstico de muerte cerebral. La hipotermia es más fácil de prevenir que de tratar, por lo que se recomienda el uso de líquidos tibios, humidificación activa de la vía aérea y equipos de calentamiento corporal.

\section{Hiperglucemia}

La hiperglucemia es frecuente y multifactorial; es secundaria al estrés, al aumento de los niveles de hormonas contrarreguladoras, al uso concomitante de esteroides, a cambios en el metabolismo de carbohidratos, a infusión de soluciones de glucosa y a la resistencia periférica a la insulina.

Blasi-Ibáñez, et al. ${ }^{62}$, demostraron la asociación entre hiperglucemia y disfunción renal posterior al trasplante. La hiperglucemia $(>180 \mathrm{mg} / \mathrm{dl})$ en el potencial donante con muerte cerebral debe ser reconocida y tratada con insulina, preferentemente por vía intravenosa, ya que su absorción por otras vías es variable y de difícil control.

Los niveles meta de glucosa en pacientes críticamente enfermos son controversiales. La mayoría de las unidades de cuidados intensivos han adoptado protocolos empíricos con niveles de glucosa meta menores de $180 \mathrm{mg} / \mathrm{dl}$, lo que parece ser apropiado también para los pacientes con muerte cerebral ${ }^{63}$.

\section{Cambios hemodinámicos}

La muerte cerebral se caracteriza por dos fases hemodinámicas. Inicialmente, existe una descarga masiva de catecolaminas, lo que conlleva un aumento de la presión arterial acompañada por varios trastornos a nivel cardiovascular. La segunda fase corresponde a una reducción acentuada de la reacción simpática, lo que, a su vez, produce un deterioro del estado inotrópico y cronotrópico, que disminuye el gasto cardiaco.

La disminución de la resistencia vascular periférica adicional a la deshidratación secundaria producida por la restricción hídrica y a la poliuria por déficit de vasopresina o por hiperglucemia, da lugar a hipovolemia e hipotensión ${ }^{64}$.

Dentro del manejo del donante potencial, uno de los objetivos más importantes es lograr una estabilidad 
cardiocirculatoria que garantice la correcta perfusión de los órganos. Las metas generales en el cuidado del donante potencial son el mantenimiento de la euvolemia y la óptima presión de perfusión (presión arterial media $\geq 60-70 \mathrm{~mm} \mathrm{Hg}$ ) ${ }^{65}$, gasto urinario entre $1 \mathrm{y}$ $3 \mathrm{ml} / \mathrm{kg} /$ hora ${ }^{66,67}$ y una fracción de eyección ventricular izquierda de, al menos, $45 \%$, con la menor cantidad de vasopresores posible ${ }^{68}$.

Las recomendaciones para el manejo son ${ }^{34}$ :

- Técnicas invasivas de monitorización

- Inserción de un catéter venoso central, de un SwanGanz o de ambos;

- Colocación de un catéter arterial

- Reanimación con líquidos intravenosos, idealmente cristaloides (solución salina al $0,9 \%$ o lactato de Ringer)

- La transfusión de gran cantidad de hemoderivados o infusión de cristaloides, coloides o ambos, puede generar hemodilución y producir falsos negativos en las muestras del donante.

- Ver la tabla 5 para comprobar si hay hemodilución.

- Infusión de vasoactivos en ausencia de reacción a los líquidos intravenosos

- La vasopresina es la alternativa de primera línea por su efecto vasopresor y antidiurético.

TABLA 5. Cálculo de la hemodilución

\begin{tabular}{ll}
\hline \multirow{2}{*}{ Volúmenes corporales } & $\begin{array}{l}\text { VP: } \mathrm{kg} / 0,025 \mathrm{ml} \\
\text { VS: } \mathrm{kg} / 0,015 \mathrm{ml}\end{array}$ \\
\hline & $\begin{array}{l}\text { Volumen total de glóbulos rojos trans- } \\
\text { fundidos en } 48 \text { horas (ml) }\end{array}$ \\
\cline { 2 - 2 } $\begin{array}{l}\text { Volúmenes de } \\
\text { infusión }\end{array}$ & $\begin{array}{l}\text { Volumen total de coloides infundidos } \\
\text { en } 48 \text { horas (ml) (coloides, plasma, } \\
\text { plaquetas, albúmina) }\end{array}$ \\
\cline { 2 - 2 } $\begin{array}{l}\text { Volumen total de cristaloides infundi- } \\
\text { dos por hora (ml) }\end{array}$ \\
\hline 2. A + B + C $>$ VS & \\
\hline 1 y/o 2 Si: Donante hemodiluido - Se descarta el donante \\
\hline 1 y/o 2 No: Donante NO hemodiluido
\end{tabular}

VP: volumen plasmático; VS: volumen sanguíneo
- La norepinefrina, la fenilefrina y otros fármacos vasoactivos pueden considerarse en casos de choque grave.

- Si las metas hemodinámicas no se logran o si la fracción de eyección ventricular izquierda permanece por debajo del $45 \%$, se recomienda utilizar la terapia de reemplazo hormonal.

\section{Cambios pulmonares}

El aumento de la presión intracraneal después de la pérdida irreversible de la función cerebral puede conducir a una lesión pulmonar inducida neurogénicamente, como resultado de la liberación de citocinas proinflamatorias. Además, como resultado de trastornos de permeabilidad capilares, puede ocurrir una extravasación capilar grave que podría condicionar edema pulmonar y déficit del volumen intravascular.

Solo 15 a $30 \%$ de los pulmones donados se pueden mantener y trasplantar con éxito. La introducción de protocolos de asistencia respiratoria protectora ha aumentado esta tasa a 25 a $54 \%$ de trasplantes exitosos de pulmón ${ }^{18}$.

Muchos intensivistas involucrados en el trasplante de pulmón prefieren la asistencia respiratoria protectora, conocida como asistencia respiratoria de bajo volumen corriente, debido a los beneficios observados entre los pacientes con síndrome de dificultad respiratoria aguda ${ }^{34}$. En la tabla 6 se exponen las principales recomendaciones de la asistencia respiratoria protectora.

El efecto de la asistencia respiratoria protectora en el número de pulmones elegibles para trasplante se evaluó en un estudio multicéntrico ${ }^{69}$. Los potenciales donantes fueron asignados aleatoriamente a asistencia respiratoria convencional (volumen corriente de 10 a $12 \mathrm{ml} / \mathrm{kg}$ de peso corporal y presión positiva al final de la espiración (PEEP) de 3 a $5 \mathrm{~cm}$ de $\mathrm{H}_{2} \mathrm{O}$ ) o asistencia respiratoria protectora (volumen corriente de 6 a $8 \mathrm{ml} / \mathrm{kg}$ de peso corporal y PEEP de 8 a $10 \mathrm{~cm}$ de $\mathrm{H}_{2} \mathrm{O}$ ) durante un período de observación de seis horas. En ambos grupos, se ajustó la frecuencia respiratoria para obtener una $\mathrm{PaCO}_{2}$ de 40 a $45 \mathrm{~mm} \mathrm{Hg}$. Treinta y dos pacientes (54\%) en el grupo con asistencia respiratoria convencional y 56 (95\%) en el grupo de asistencia respiratoria protectora, cumplieron con los criterios de elegibilidad de los 
TABLA 6.

Asistencia respiratoria protectora

Asistencia respiratoria controlada por volumen, regulada por presión Volumen corriente de $6-8 \mathrm{ml}$ por $\mathrm{kg}$ de peso corporal calculado

Presión de meseta $<30 \mathrm{~cm}$ de $\mathrm{H}_{2} \mathrm{O}$ (si no está disponible en el respirador; presión máxima $<35 \mathrm{~cm}$ de $\mathrm{H}_{2} \mathrm{O}$ )

PEEP de 8-10 cm de $\mathrm{H}_{2} \mathrm{O}$, si la función pulmonar está alterada, aumentar a $15 \mathrm{~cm}$ de $\mathrm{H}_{2} \mathrm{O}$

$\mathrm{FiO}_{2}$ mínima para mantener una saturación de, al menos, 92-95\%

Medidas de reclutamiento alveolar

Higiene bronquial regular, si se requiere broncoscopia

Protocolo de posicionamiento del paciente para prevenir periodos prolongados en posición supina (menos de $30^{\circ}$ de elevación de la cabecera)

Desinfección de las manos antes de la manipulación del aparato respiratorio

Higiene oral y descontaminación

Extraído de: Hahnenkamp, et al. ${ }^{18}$

donantes de pulmón. Las tasas de supervivencia a los seis meses de los receptores de trasplante de pulmón no difirieron entre los dos grupos. Consecuentemente, si el estado hemodinámico y el acidobásico lo permiten, una estrategia de asistencia respiratoria de bajo volumen corriente para potenciales donantes de pulmón podría aumentar la proporción de pulmones aceptados para trasplante.

Los criterios estándar para la donación de pulmón estipulan que los donantes deben tener una relación $\mathrm{PaO}_{2} / \mathrm{FiO}_{2}$ de más de $300 \mathrm{~mm} \mathrm{Hg}$, es decir, una $\mathrm{PaO}_{2}$ mayor de $300 \mathrm{~mm} \mathrm{Hg}$ con $100 \%$ de $\mathrm{FiO}_{2}$ y PEEP de $5 \mathrm{~cm}$ de $\mathrm{H}_{2} \mathrm{O}^{34}$. No obstante, aunque en la mayoría de los centros se respete este umbral para la selección de los donantes, existe una experiencia limitada y contradictoria de aquellos donantes en los que no se respeta esta norma.

En un estudio retrospectivo de Thabut, et al. ${ }^{70}$, se observó que los donantes con una relación $\mathrm{PaO}_{2} / \mathrm{FiO}_{2}$ menor de $350 \mathrm{~mm} \mathrm{Hg}$ tenían un aumento importante del riesgo de muerte. En contraste, Luckraz, et al. ${ }^{71}$, revisaron retrospectivamente 362 pares de donantes y receptores por un periodo de 17 años, y no encontraron diferencias en la supervivencia al año y a los cinco años en los receptores de donantes con $\mathrm{PaO}_{2} / \mathrm{FiO}_{2}$ menor de $300 \mathrm{~mm} \mathrm{Hg}$, en comparación con aquellos receptores de donantes con $\mathrm{PaO}_{2} / \mathrm{FiO}_{2}$ mayor de $300 \mathrm{~mm} \mathrm{Hg}$.

\section{Cambios hepáticos}

Respecto a los cambios en el hígado, es importante tener en cuenta los factores que se han asociado con resultados adversos después del trasplante hepático; algunos de estos son edad avanzada, esteatosis hepática, tiempo prolongado de isquemia en frío, incompatibilidad $\mathrm{ABO}$ e inestabilidad hemodinámica del donante ${ }^{72,73}$.

Los períodos de hipotensión en el donante con muerte cerebral se han asociado con reducción de la función del injerto hepático y aumento de la estancia hospitalaria del receptor, en estudios retrospectivos ${ }^{74,75}$. Además, el uso de altas dosis de vasopresores en el potencial donante hepático predisponen a lesión hepática isquémica; no obstante, su administración no contraindica el uso del órgano para trasplante $18,76,77$.

\section{Cambios de electrolitos y función renal}

Como consecuencia de las alteraciones cardiovasculares y endocrinas generadas por la muerte cerebral, acompañadas de la reanimación exhaustiva con líquidos intravenosos para mantener la presión arterial media, es frecuente observar alteraciones del equilibrio electrolítico en el donante y cambios dinámicos en la excreción renal que están estrechamente relacionados.

Después de la muerte cerebral, las alteraciones en otros sistemas pueden tener repercusión sobre la función renal y el equilibrio electrolítico del donante y causar su exclusión como donante potencial o generar problemas posteriores en los receptores.

El déficit de secreción de vasopresina genera poliuria, la cual, de no ser manejada apropiadamente, puede desencadenar hipotensión, falla renal aguda e hipernatremia. Los estudios de Kazemeyni, et al. ${ }^{78}$, y Kwiatkowska, et al. ${ }^{79}$, han demostrado que la hipernatremia y el incremento en la osmolaridad plasmática de los donantes puede influir a largo plazo sobre los niveles séricos de creatinina de los receptores renales.

En ausencia de hipernatremia, se recomienda realizar la reposición hídrica con solución salina al 0,9\% o 
lactato de Ringer, prefiriéndose este último por evitar la acidosis hiperclorémica ${ }^{80}$. En presencia de hipernatremia, se recomiendan las soluciones medio isotónicas con bicarbonato o sin él o, incluso, la dextrosa al $5 \%$ en agua destilada. La meta es tener valores de sodio inferiores a $150 \mathrm{mmol} / \mathrm{L}$ en presencia de diabetes insípida y niveles entre 135 y $145 \mathrm{mmol} / \mathrm{L}$ en su ausencia ${ }^{18}$.

En cuanto al potasio, su alteración es menos frecuente; la recomendación es mantener los niveles entre 3,5 y $5 \mathrm{mmol} / \mathrm{L}^{18}$.

El uso de coloides sintéticos no se recomienda de manera regular en el mantenimiento de los donantes con muerte cerebral, debido a su asociación con daño en la células epiteliales renales y posterior disfunción temprana del injerto en los riñones trasplantados ${ }^{81}$.

\section{Donantes de criterios extendidos en trasplante hepático y renal}

En la última década, la utilización de órganos de donantes mayores y de otros donantes con alteraciones fisiológicas, se ha convertido en una práctica común, con la que se han logrado resultados satisfactorios ${ }^{6,82}$. El concepto de "donantes con criterios extendidos" (Extended Criteria Donors, ECD) agrupa un conjunto de donantes cadavéricos que representan un mayor riesgo de disfunción primaria y fracaso del injerto, en comparación con los receptores de donantes con criterios estándar ${ }^{83-85}$.

La problemática del aumento de pacientes en listas de espera de trasplantes ha orientado los esfuerzos hacia los donantes de órganos con criterios extendidos, ya que estos no representan ningún esfuerzo mayor en el mantenimiento del donante $y$, por el contrario, pueden ayudar a disminuir el número de pacientes en lista de espera.

En un estudio retrospectivo de casos y controles entre donantes de riñón con muerte cerebral y con falla renal aguda, y donantes con muerte cerebral sin falla renal aguda, se encontró que, en el seguimiento a un año, los receptores de donantes con muerte cerebral y con falla renal aguda no tenían diferencia en los niveles basales de creatinina sérica y proteinuria con respecto a los donantes sin falla renal aguda ${ }^{86}$.

En estos casos, es necesario que los donantes con criterios extendidos cumplan con los criterios establecidos $\mathrm{y}$, además, se haga una biopsia del injerto, la cual aporta información sobre el pronóstico y ayuda a tomar decisiones clínicas sobre la viabilidad del órgano, antes del implante en el receptor (índice de Remuzzi para riñón) ${ }^{85}$ (tabla 7).

\section{Discusión}

Colombia es un país con bajos índices de donación y altas necesidades de trasplantes, con una lista de espera que cada año aumenta exponencialmente. Se han realizado esfuerzos para tratar de suplir esta necesidad, como fue la creación de la Red de Donación y Trasplantes de Órganos y Tejidos por el Ministerio de la Protección Social. Además, en los últimos años ha habido un aumento de las IPS que practican trasplantes y una mayor sensibilización del tema por parte de la población general. No obstante, aún contamos con barreras sociales y culturales que impiden la donación.

Por otra parte, el manejo de los donantes de órganos con muerte cerebral sigue siendo crítico y la falta de un soporte fisiológico adecuado se ha considerado la causa del $25 \%$ de las fallas en la obtención de órganos ${ }^{87}$. Se ha demostrado que la estandarización del manejo del paciente crítico con muerte cerebral puede ayudar a mejorar la inconsistencia de la gestión de los donantes $\mathrm{y}$, a su vez, puede aumentar el número y la calidad de los órganos adquiridos y trasplantados ${ }^{10}$.

En esta revisión, se exponen las recomendaciones internacionales del manejo del potencial donante con

TABLA 7.

Criterios extendidos para donantes de riñón o hígado

\begin{tabular}{|c|c|}
\hline Riñón & Hígado \\
\hline $\begin{array}{l}>60 \text { años o } 50-59 \text { años que cumpla } \\
\text { dos de los tres siguientes criterios }\end{array}$ & \multirow{3}{*}{$\begin{array}{l}\text { Pacientes }>40 \text { años } \\
\text { Obesidad } \\
\text { Esteatosis hepática }(>30 \%) \\
\text { Necesidad de altas dosis de } \\
\text { inotrópicos } \\
\text { Sodio sérico }>160 \mathrm{mEq} / \mathrm{L} \\
\text { Serología positiva para he- } \\
\text { patitis B o C } \\
\text { Tumores }\end{array}$} \\
\hline $\begin{array}{l}\text { Muerte por un evento cardiovascular } \\
\text { Historia de hipertensión arterial } \\
\text { sistémica } \\
\text { Creatinina sérica }>1,5 \mathrm{mg} / \mathrm{dl}\end{array}$ & \\
\hline $\begin{array}{l}\text { Índice de Remuzzi: para definir tras- } \\
\text { plante en bloque o sencillo } \\
\text { Si la suma es } \\
\leq 3 \text { : se trasplanta un solo riñón } \\
4 \text { a } 6 \text { : trasplantar los dos riñones } \\
\text { simultáneamente } \\
\geq 7 \text { : descartar los riñones }\end{array}$ & \\
\hline
\end{tabular}


muerte cerebral, las cuales esperamos se puedan adoptar en los protocolos institucionales para optimizar su manejo en Colombia y, así, aumentar el número de trasplantes y suplir las necesidades de los pacientes (tabla 8).
En la figura 6 se exponen nuestras recomendaciones finales, las cuales sugerimos tener en cuenta en todo el proceso de donación, desde el momento de la alerta del potencial donante, hasta la cirugía para obtener los órganos y tejidos.

TABLA 8.

Exámenes que se deben solicitar en el potencial donante

Tomar tubos de sangre antes de la administración masiva de líquidos o hemoderivados, con el fin de evitar la hemodilución

4 tubos secos

4 tubos con anticoagulante

\begin{tabular}{ll}
\hline Exámenes paraclínicos & Pruebas de infección \\
\hline Donantes estándar & - HIV I y II \\
- Hemoclasificación y hemograma & - HTLV I y II \\
- Tiempos de coagulación & - Virus de Epstein-Barr (IgG) \\
- BUN y creatinina & - Toxoplasma gondii (IgG e IgM) \\
- AST, ALT, bilirrubinas, fosfatasa alcalina & - Citomegalovirus (IgG e IgM) \\
- LDH & - Serología para sífilis (RPR) \\
- Electrolitos (Na, Cl, $\mathrm{K}, \mathrm{Ca}, \mathrm{Mg})$ & - Trypanosoma cruzi (Chagas) (IgG) \\
- Glucemia & - Dengue (IgM, IgG, e NS1) \\
- Ácido láctico & - Hepatitis B core (IgG e IgM) \\
- Uroanálisis & - Hepatitis B (anticuerpos contra antígenos de superficie) \\
- Troponina I (CPK, CPK-MB) & - Hepatitis B (antígenos de superficie) \\
- PSA (hombres mayores de 50 años) & - Hepatitis C (IgG) \\
- Gases arteriales (cálculo PaO ${ }_{2} / \mathrm{FiO}_{2}$ ) (potencial donante de pulmón) & \\
- Amilasa, lipasa y HbAlc (potencial donante de páncreas) & \\
\hline Donantes con criterios extendidos & \\
- Indice proteinuria/creatinuria & \\
- Microalbuminuria & \\
\hline
\end{tabular}

BUN: nitrógeno ureico; AST: aspartato aminotransferasa; ALT: alanina transaminasa; LDH: lactato deshidrogenasa; CPK: creatininfosfocinasa; CPK-MB: creatininfosfocinasa de origen cardiaco; PSA: antígeno prostático específico; HbA1c: hemoglobina 'glucosilada'; VIH: virus de la inmunodeficiencia humana; HTLV: virus linfotrópico de células T humanas

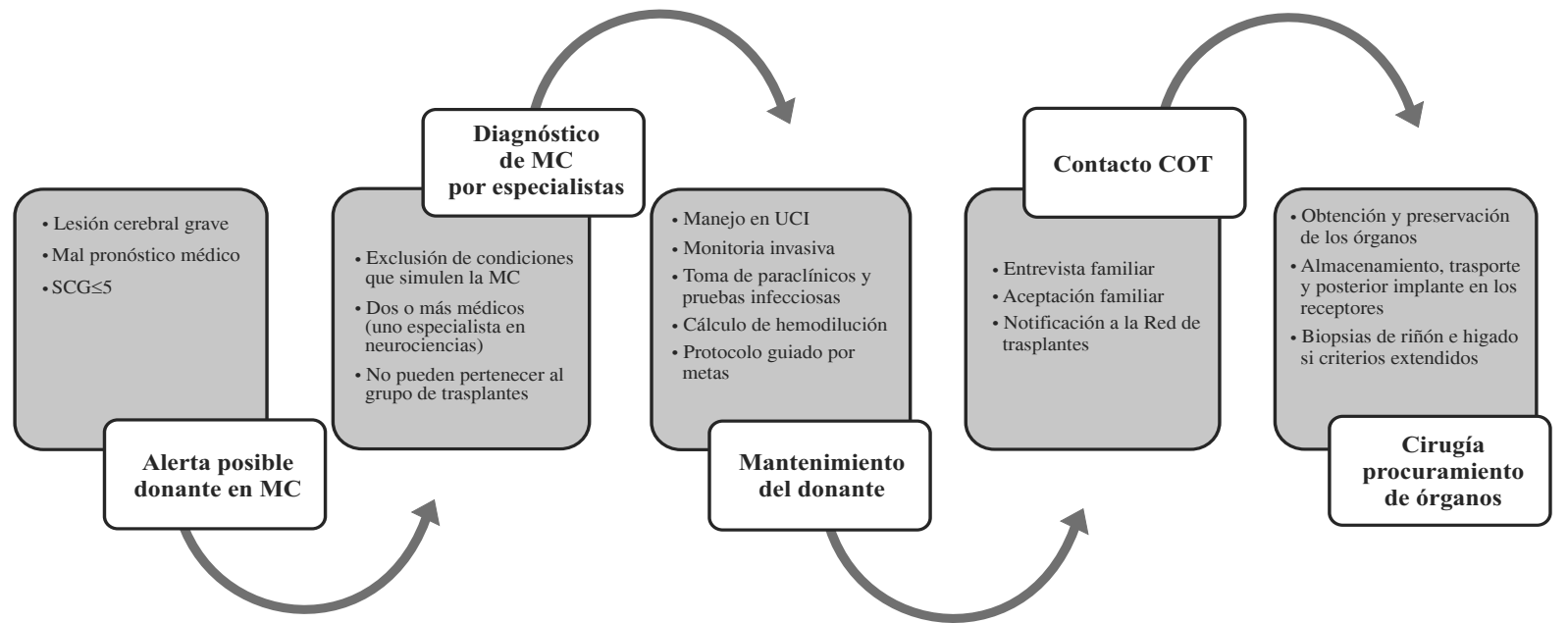

Figura 6. Proceso de donación de órganos y tejidos

MC: muerte cerebral; SCG: escala de coma de Glasgow; UCI: unidad de cuidado intensivo; COT: coordinador operativo de trasplantes 


\title{
Current management of potential organ and tissue donors in brain death: management guideline and literature review
}

\begin{abstract}
In many cases organ transplantation is the only therapeutic option for patients with terminal essential organ diseases; however, there is an imbalance between the number of organs available and the number of potential receptors for transplants worldwide.

Patients with brain death are the main source of organs for transplantation. Promoting early recognition of measures that prevent damage of organs in brain death organ donors is essential for appropriate clinical management. In this framework, it is known that aggressive clinical management of those potential organ donors using standardized protocols are associated with a greater number of transplanted organs and the reduction of the loss of potential donors by cardiac arrest.

Colombia is a country with low donation rates and high transplant needs, with a waiting list that increases exponentially each year. In this review we present the international recommendations of potential organ donors management, which we hope can be adopted in institutional protocols to optimize the management of potential donors in Colombia, thus increasing transplants and meeting the needs of the patients.
\end{abstract}

Key words: Transplantation; organ transplantation; donor selection; tissue and organ procurement; brain death.

\section{Referencias}

1. Westphal GA, Slaviero TA, Montemezzo A, Lingiardi GT, de Souza FCC, Carnin TC, et al. The effect of brain death protocol duration on potential donor losses due to cardiac arrest. Clin Transplant. 2016;30:1411-6.

2. McKeown DW, Bonser RS, Kellum JA. Management of the heartbeating brain-dead organ donor. Br J Anaesth. 2012;108(Suppl.1):i96-107.

3. Klein AS, Messersmith EE, Ratner LE, Kochik R, Baliga PK, Ojo AO. Organ donation and utilization in the United States, 1999-2008. Am J Transplant Off J Am Soc Transplant Am Soc Transpl Surg. 2010;10:973-86.

4. Transplant Activity in the UK. Activity Report 2010/11. NHS Blood and Transplant. Fecha de consulta: 29 de noviembre de 2016. Disponible en: http://www.organdonation.nhs.uk/ukt/ statistics/transplant_activity_report/transplant_activity_report. jsp.

5. Oosterlee A, Rahmel A, editors. Annual Report 2010. Eurotransplant International Foundation, The Netherlands. 2010. fecha de consulta: 29 de noviembre de 2016. Disponible en: http://www. eurotransplant.org/cms/index.php?page=annual_reports.

6. Matesanz R, Domínguez-Gil B, Coll E, Mahíllo B, Marazuela R. How Spain reached 40 deceased organ donors per million population. Am J Transplant. 2017. Fecha de consulta: 20 de enero de 2017. Disponible en: http://onlinelibrary.wiley.com/ doi/10.1111/ajt.14104/abstract. doi: 10.1111/ajt.14104.
7. Westphal GA, Garcia VD, Souza RL de, Franke CA, Vieira KD, Birckholz VRZ, et al. Guidelines for the assessment and acceptance of potential brain-dead organ donors. Rev Bras Ter Intensiva. 2016;28:220-55.

8. Salim A, Velmahos GC, Brown C, Belzberg H, Demetriades D. Aggressive organ donor management significantly increases the number of organs available for transplantation. J Trauma. 2005;58:991-4.

9. Franklin GA, Santos AP, Smith JW, Galbraith S, Harbrecht BG, Garrison RN. Optimization of donor management goals yields increased organ use. Am Surg. 2010;76:587-94.

10. Malinoski DJ, Daly MC, Patel MS, Oley-Graybill C, Foster CE, Salim A. Achieving donor management goals before deceased donor procurement is associated with more organs transplanted per donor. J Trauma. 2011;71:990-6.

11. Domínguez-Gil B, Coll E, Pont T, Lebrón M, Miñambres E, Coronil A, et al. End-of-life practices in patients with devastating brain injury in Spain: Implications for organ donation. Med Intensiva. 2016;14:162-173. doi: 10.1016/j.medin.2016.07.011.

12. Wauters S, Verleden GM, Belmans A, Coosemans W, De Leyn P, Nafteux P, et al. Donor cause of brain death and related time intervals: Does it affect outcome after lung transplantation? Eur J Cardio-Thorac Surg Off J Eur Assoc Cardio-Thorac Surg. 2011;39:e68-76. 
13. Shemie SD, Ross H, Pagliarello J, Baker AJ, Greig PD, Brand T, et al. Organ donor management in Canada: Recommendations of the forum on Medical Management to Optimize Donor Organ Potential. CMAJ Can Med Assoc J J Assoc Medicale Can. 2006;174:S13-32.

14. Estella A, Martín MC, Hernández A, Rubio O, Monzón JL, Cabré L, et al. End of life critical patients: A multicenter study in Spanish intensive care units. Med Intensiva. 2016;40:448-50.

15. Escudero D, Otero J. Intensive care medicine and organ donation: Exploring the last frontiers? Med Intensiva. 2015;39:373-81.

16. Novitzky D, Cooper DK. The brain-dead organ donor. New York: Springer; 2012. Fecha de consulta: 29 de noviembre de 2016. Disponible en: http://www.ebooks.com/1030419/the-brain-deadorgan-donor/novitzky-dimitri-ed--cooper-david-k-c-ed/.

17. Youn TS, Greer DM. Brain death and management of a potential organ donor in the intensive care unit. Crit Care Clin. 2014;30:813-31.

18. Hahnenkamp K, Böhler K, Wolters H, Wiebe K, Schneider D, Schmidt HH-J. Organ-protective intensive care in organ donors. Dtsch Arzteblatt Int. 2016;113:552-8.

19. Ospina ML, Beltrán M, Segura A. Informe anual Red de Donación y Trasplantes, Colombia, año 2015. Bogotá: Instituto Nacional de Salud, Coordinación Nacional Red Donación y Trasplantes; 2016.

20. Holguín AJ, Rodríguez-Takeuchi S, Ospina L, Acosta D, Botero $\mathrm{V}$, Thomas L, et al. Biliary strictures complicating liver transplantation in pediatric patients: Experience in a South American transplant center. Clin Transplant. 2017;31. doi: 10.1111/ ctr. 12877 .

21. Caicedo L, Gómez JC, Serrano O, Manzi E, Posada JG, Mesa L. et al. Derivación exocrina al duodeno en trasplante simultáneo de riñón y páncreas, experiencia en la Fundación Valle de Lili, Cali, Colombia. Rev Colomb Cir. 2016;31:178-84.

22. Millán M, Delgado A, Caicedo LA, Arrunategui AM, Meneses CA, Villegas JI, et al. Liver angiosarcoma: Rare tumour associated with a poor prognosis, literature review and case report. Int J Surg Case Rep. 2016;28:165-8.

23. Millán M, Caicedo LA, Villegas JI, Serrano O, Caicedo L, Duque $\mathrm{M}$, et al. Case report of cadaveric kidney transplantation with renal-portal venous drainage: A feasible way for a venous drainage in a complex generalized thrombosed vessels setting. Int J Surg Case Rep. 2016;28:192-5.

24. Serrano ÓJ, Villegas JI, Echeverri GJ, Posada JG, Mesa L, Schweineberg J, et al . Trasplante simultáneo de riñón y páncreas en pacientes con diabetes mellitus de tipo 1, Clínica Fundación Valle del Lili, Cali, 2001-2013. Rev Colomb Cir. 2014;29:32-41.

25. Sabogal A, Casas LA, Arango LG, Feriz K, Guzmán G, Gutiérrez Ó, et al. Presente y futuro del trasplante de islotes pancreáticos, un tratamiento innovador para la diabetes tipo 1. Rev Colomb Endocrinol Diabetes Metab. 2015;2:20-30.

26. Echeverri GJ, Sabogal AN, Caicedo LA, Casas LA, Mesa L, Schweineberg J, et al. Primer trasplante de islotes realizado en
Colombia, experiencia fundación Valle del Lili. Rev Colomb Endocrinol Diabetes Metab. 2015;2:33-9.

27. Caicedo LA, Gómez JC, Duque MF, Serrano ÓJ, Manzi E, Arrunátegu AM, et al. Trasplante renal con HLA idéntico de donante vivo y cadavérico: experiencia de la Fundación Valle de Lili, Cali, Colombia. Rev Colomb Cir. 2016;31:170-7.

28. Caicedo LA, Vernaza C, Valderrama ML, Manzi E, Echeverri GJ, Jiménez DF, et al. The experience of the Fundacion Valle del Lili in Cali, Colombia with combined liver and kidney transplantation. Rev Col Gastroenterol. 2016;31:96-101.

29. Caicedo LA, Villegas JI, Serrano O, Millán M, Sepúlveda M, Jiménez D, et al. En-bloc transplant of the liver, kidney and pancreas: Experience from a Latin American transplant center. Am J Case Rep. 2017;18:114-8.

30. Caicedo L, Buitrago D, Thomas L, Villegas J, Duque M, Serrano $\mathrm{O}$, et al. Liver transplantation for unresectable metastases from colon adenocarcinoma. Case Rep Gastroenterol. 2016;10: 808-13.

31. Wijdicks EF. The diagnosis of brain death. N Engl J Med. 2001;344:1215-21.

32. Cantrill SV. Brain death. Emerg Med Clin North Am. 1997; 15:713-22.

33. Wijdicks EFM. The neurologist and Harvard criteria for brain death. Neurology. 2003;61:970-6.

34. Kotloff RM, Blosser S, Fulda GJ, Malinoski D, Ahya VN, Angel $\mathrm{L}$, et al. Management of the potential organ donor in the ICU: Society of Critical Care Medicine/American College of Chest Physicians/Association of Organ Procurement Organizations Consensus Statement. Crit Care Med. 2015;43:1291-325.

35. Wijdicks EFM, Varelas PN, Gronseth GS, Greer DM. Evidencebased guideline update: Determining brain death in adults Report of the Quality Standards Subcommittee of the American Academy of Neurology. Neurology. 2010;74:1911-8.

36. Ministerio de Protección Social. Decreto 2493 del 2004. Sect. sec. Capítulo III. Diagnóstico de muerte encefálica. Bogotá, D.C., Colombia. Fecha de consulta: 29 de noviembre de 2016. Disponible en: http:/www.alcaldiabogota.gov.co/sisjur/normas/ Norma1.jsp? $\mathrm{i}=14525$.

37. Solek-Pastuszka J, Sawicki M, Iwanczuk W, Bohatyrewicz R. Ventilator-delivered continuous positive airway pressure for apnea test in the diagnosis of brain death in patient with extremely poor baseline lung function-case report. Transplant Proc. 2016;48:2471-2.

38. Algin O, Gundogdu G, Izdes S, Keles GE, Solaroglu I. Diagnosis of brain death by orbital Doppler ultrasound: A comparative research study. Turk Neurosurg. 2015;25:256-62.

39. Walter U, Schreiber SJ, Kaps M. Doppler and Duplex sonography for the diagnosis of the irreversible cessation of brain function ("brain death"): Current Guidelines in Germany and Neighboring Countries. Ultraschall in Med. 2016;37:558-78. doi: 10.1055/s0042-112222. 
40. Roa JD. Muerte encefálica en pediatría. Sociedad Colombiana de Pediatría. 2015;14:44-56.

41. Chen EP, Bittner HB, Kendall SW, van Trigt P. Hormonal and hemodynamic changes in a validated animal model of brain death. Crit Care Med. 1996;24:1352-9.

42. Novitzky D, Cooper DK, Morrell D, Isaacs S. Change from aerobic to anaerobic metabolism after brain death, and reversal following triiodothyronine therapy. Transplantation. 1988;45:326.

43. Salim A, Vassiliu P, Velmahos GC, Sava J, Murray JA, Belzberg $\mathrm{H}$, et al. The role of thyroid hormone administration in potential organ donors. Arch Surg. 2001;136:1377-80.

44. Rosendale JD, Kauffman HM, McBride MA, Chabalewski FL, Zaroff JG, Garrity ER, et al. Aggressive pharmacologic donor management results in more transplanted organs. Transplantation. 2003;75:482-7.

45. Novitzky D, Cooper DKC, Rosendale JD, Kauffman HM. Hormonal therapy of the brain-dead organ donor: Experimental and clinical studies. Transplantation. 2006;82:1396-401.

46. Gramm HJ, Meinhold H, Bickel U, Zimmermann J, von Hammerstein B, Keller F, et al. Acute endocrine failure after brain death? Transplantation. 1992;54:851-7.

47. Novitzky D, Mi Z, Sun Q, Collins JF, Cooper DKC. Thyroid hormone therapy in the management of 63,593 brain-dead organ donors: A retrospective analysis. Transplantation. 2014;98:111927.

48. Novitzky D, Mi Z, Videla LA, Collins JF, Cooper DKC. Hormone resuscitation therapy for brain-dead donors - is insulin beneficial or detrimental? Clin Transplant. 2016;30:754-9.

49. Smith M. Physiologic changes during brain stem death--lessons for management of the organ donor. J Heart Lung Transplant. 2004;23(Suppl.):S217-22.

50. Salim A, Martin M, Brown C, Belzberg H, Rhee P, Demetriades D. Complications of brain death: Frequency and impact on organ retrieval. Am Surg. 2006;72:377-81.

51. Chen JM, Cullinane S, Spanier TB, Artrip JH, John R, Edwards $\mathrm{NM}$, et al. Vasopressin deficiency and pressor hypersensitivity in hemodynamically unstable organ donors. Circulation. 1999;100(Suppl.):II244-6.

52. Pennefather SH, Bullock RE, Mantle D, Dark JH. Use of low dose arginine vasopressin to support brain-dead organ donors. Transplantation. 1995;59:58-62.

53. Holmes CL, Patel BM, Russell JA, Walley KR. Physiology of vasopressin relevant to management of septic shock. Chest. 2001;120:989-1002.

54. Torgersen C, Dünser MW, Wenzel V, Jochberger S, Mayr V, Schmittinger CA, et al. Comparing two different arginine vasopressin doses in advanced vasodilatory shock: A randomized, controlled, open-label trial. Intensive Care Med. 2010;36:57-65.

55. Richardson DW, Robinson AG. Desmopressin. Ann Intern Med. 1985;103:228-39.
56. Mannucci PM. Hemostatic drugs. N Engl J Med. 1998;339:24553.

57. Weiss S, Kotsch K, Francuski M, Reutzel-Selke A, Mantouvalou L, Klemz R, et al. Brain death activates donor organs and is associated with a worse $\mathrm{I} / \mathrm{R}$ injury after liver transplantation. Am J Transplant. 2007;7:1584-93.

58. McKeating EG, Andrews PJ, Signorini DF, Mascia L. Transcranial cytokine gradients in patients requiring intensive care after acute brain injury. Br J Anaesth. 1997;78:520-3.

59. Stangl M, Zerkaulen T, Theodorakis J, Illner W, Schneeberger $\mathrm{H}$, Land $\mathrm{W}$, et al. Influence of brain death on cytokine release in organ donors and renal transplants. Transplant Proc. 2001;33:1284-5.

60. Follette DM, Rudich SM, Babcock WD. Improved oxygenation and increased lung donor recovery with high-dose steroid administration after brain death. J J Heart Lung Transplant.1998;17:423-9.

61. McElhinney DB, Khan JH, Babcock WD, Hall TS. Thoracic organ donor characteristics associated with successful lung procurement. Clin Transplant. 2001;15:68-71.

62. Blasi-Ibáñez A, Hirose R, Feiner J, Freise C, Stock PG, Roberts $\mathrm{JP}$, et al. Predictors associated with terminal renal function in deceased organ donors in the intensive care unit. Anesthesiology. 2009;110:333-41.

63. The NICE-SUGAR Study Investigators. Intensive versus conventional glucose control in critically ill patients. N Engl J Med. 2009;360:1283-97.

64. Echeverri G. J. El donante de órganos y tejidos. Universitas Medicas. 2006;47:228-40.

65. Mascia L, Mastromauro I, Viberti S, Vincenzi M, Zanello M. Management to optimize organ procurement in brain dead donors. Minerva Anestesiol. 2009;75:125-33.

66. Wood KE, Becker BN, McCartney JG, D’Alessandro AM, Coursin DB. Care of the potential organ donor. N Engl J Med. 2004;351:2730-9.

67. O'Connor KJ, Wood KE, Lord K. Intensive management of organ donors to maximize transplantation. Crit Care Nurse. 2006;26:94-100.

68. Maciel CB, Greer DM. ICU management of the potential organ donor: State of the art. Curr Neurol Neurosci Rep. 2016;16:86.

69. Mascia L, Pasero D, Slutsky AS, Arguis MJ, Berardino M, Grasso S, et al. Effect of a lung protective strategy for organ donors on eligibility and availability of lungs for transplantation: A randomized controlled trial. JAMA. 2010;304:2620-7.

70. Thabut G, Mal H, Cerrina J, Dartevelle P, Dromer C, Velly J-F, et al. Influence of donor characteristics on outcome after lung transplantation: A multicenter study. J Heart Lung Transplant. 2005;24:1347-53

71. Luckraz H, White P, Sharples LD, Hopkins P, Wallwork J. Shortand long-term outcomes of using pulmonary allograft donors with low Po2. J Heart Lung Transplant. 2005;24:470-3. 
72. Corradini SG, Elisei W, De Marco R, Siciliano M, Iappelli M, Pugliese F, et al. Preharvest donor hyperoxia predicts good early graft function and longer graft survival after liver transplantation. Liver Transpl. 2005;11:140-51.

73. Kim JM, Kwon CHD, Joh J-W, Kang E-S, Park JB, Lee JH, et al. ABO-incompatible living donor liver transplantation is suitable in patients without ABO-matched donor. J Hepatol. 2013;59:1215-22.

74. de laTorre AN, Kuo PC, Plotkin JS, Ridge LA, Howell CD, Bartlett ST, et al. Influence of donor base deficit status on recipient outcomes in liver transplantation. Transplant Proc. 1997;29:474.

75. Mimeault R, Grant D, Ghent C, Duff J, Wall W. Analysis of donor and recipient variables and early graft function after orthotopic liver transplantation. Transplant Proc. 1989;21:3355.

76. Totsuka E, Fung U, Hakamada K, Tanaka M, Takahashi K, Nakai $\mathrm{M}$, et al. Analysis of clinical variables of donors and recipients with respect to short-term graft outcome in human liver transplantation. Transplant Proc. 2004;36:2215-8.

77. Totsuka E, Fung JJ, Ishii T, Urakami A, Moras NP, Hakamada $\mathrm{K}$, et al. Influence of donor condition on postoperative graft survival and function in human liver transplantation. Transplant Proc. 2000;32:322-6.

78. Kazemeyni SM, Esfahani F. Influence of hypernatremia and polyuria of brain-dead donors before organ procurement on kidney allograft function. Urol J. 2008;5:173-7.

79. Kwiatkowska E, Bober J, Ciechanowski K, Kadzierska K, Gotmbiewska E. Increased serum sodium values in brain-dead donor's influences its long-term kidney function. Transplant Proc. 2013;45:51-6.

80. Wood KE, McCartney J. Management of the potential organ donor. Transplant Rev. 2007;21:204-18.
81. Cittanova ML, Leblanc I, Legendre C, Mouquet C, Riou B, Coriat $\mathrm{P}$. Effect of hydroxyethylstarch in brain-dead kidney donors on renal function in kidney-transplant recipients. Lancet Lond Engl. 1996;348:1620-2.

82. Tomita Y, Tojimbara T, Iwadoh K, Nakajima I, Fuchinoue S. Long-term outcomes in kidney transplantation from expanded-criteria donors after circulatory death. Transplant Proc. 2017;49:45-8.

83. Metzger RA, Delmonico FL, Feng S, Port FK, Wynn JJ, Merion RM. Expanded criteria donors for kidney transplantation. Am J Transplant. 2003;3(Suppl.4):114-25.

84. Melilli E, Bestard O, Cruzado J, Navarro I, Grinyó J, Martínez A. Trasplante de riñones con criterios expandidos: manejo y resultados a largo plazo. Nefrol Supl Extraordin. 2011;2:98-104.

85. Serón D, Anaya F, Marcén R, del Moral RG, Martul EV, Alarcón A, et al. Guidelines for indicating, obtaining, processing and evaluating kidney biopsies. Nefrología. 2008;28:385-96.

86. Benck U, Schnuelle P, Krüger B, Nowak K, Riester T, Mundt H, et al. Excellent graft and patient survival after renal transplantation from donors after brain death with acute kidney injury: A case-control study. Int Urol Nephrol. 2015;47:2039-46.

87. Mackersie RC, Bronsther OL, Shackford SR. Organ procurement in patients with fatal head injuries. The fate of the potential donor. Ann Surg. 1991;213:143-50.

Correspondencia: Gabriel J. Echeverri, MD

Correo electrónico: gjecheverri@icesi.edu.co; gjecheverri@hotmail.com

Cali, Colombia 